\title{
Alteração mineralógica de Neossolos em uma climo-litossequência no Planalto do Rio Grande do Sul
}

\author{
Mineral weathering in Neossolos in a climo-litosequence on the Rio Grande do Sul Plateau, Brazil
}

\author{
Fabrício de Araújo Pedron ${ }^{\mathrm{I}}$ Antonio Carlos de AzevedoII Ricardo Simão Diniz Dalmolin ${ }^{\text {III }}$
}

\section{RESUMO}

No Estado do Rio Grande do Sul (RS), os Neossolos Litólicos e Neossolos Regolíticos são solos que têm sofrido forte pressão de uso, demandando maior conhecimento sobre sua gênese e mineralogia. O objetivo deste trabalho foi determinar o grau de intemperismo de Neossolos Litólicos e Neossolos Regolíticos, avaliando-se a alteração dos minerais em perfis dispostos em uma climo-litossequência no Planalto do RS, através de técnicas de dissolução química e difração de raios $X$. Foram identificados dois grupos de solos com graus de alteração distintos. O primeiro é constituído pelos perfis da porção Oeste da climo-litossequência (P1, P2 e P3) e encontrase no estádio entre a bissialitização e a monossialitização, com predomínio de esmectita com hidroxi-Al entrecamadas (EHE), caulinita e hematita na fração argila. O segundo é representado pelos perfis da porção Leste (P4 e P5), encontrando-se no estádio entre a monossialitização e a ferralitização, com predomínio de caulinita e goethita e presença de gibbsita e EHE na fração argila. Os resultados sugerem maior influência do clima na alteração dos perfis. Os índices ki e kr não foram eficientes em representar a condição de alteração secundária dos perfis de Neossolos.

Palavras-chave: mineralogia, saprolito, solos subtropicais, pedogênese.

\section{ABSTRACT}

In the Rio Grande do Sul state (RS) Neossolos Litólicos (Leptosols) and Neossolos Regolíticos (Regosols) are soils that have been suffering strong use pressure, demanding better knowledge on their genesis and mineralogy than the existing one. The objective of this research was to determine the weathering degree of Neossolos Litólicos and Neossolos
Regoliticos through the evaluation of the minerals alteration in profiles disposed in a climo-litossequence in the RS Plateau, using techniques of chemical dissolution and $X$ rays diffraction. The authors identified two groups of soils with different alteration degree. The first one is composed by the profiles of the West portion of the climo-litossequence (P1, P2 and P3) which has the weathering degree between the bissialitization and the monossialitization, with high content of smectite with hidroxiAl interlayers (EHE), caulinite and hematite in the clay fraction. The second one is represented by the profiles of the East portion (P4 and P5), with weathering degree between the monossialitization and the ferralitization, with high content of caulinite and goethite and presence of gibbsite and EHE in the clay. The results suggested an higher contribution of the climate on the weathering of the profiles. The ki and $\mathrm{kr}$ indexes were not efficient in representing the condition of secondary alteration of the profiles of Neossolos.

Key words: mineralogy, saprolite, subtropical soils, pedogenesis.

\section{INTRODUÇÃO}

Os Neossolos Litólicos e Neossolos Regolíticos são solos que apresentam, respectivamente, contato saprolítico (PEDRON et al., 2009) e contato lítico (EMBRAPA, 2006) relativamente próximo à superfície, o que influencia o seu potencial agrícola e não agrícola. São solos pouco pesquisados devido ao seu baixo potencial, porém, nas últimas décadas, a pressão de uso agrícola e ubano vem justificando a

IDepartamento de Solos, Universidade Federal de Santa Maria (UFSM), 97105-900, Santa Maria, RS, Brasil. E-mail: fapedron@ufsm.br. Autor para correspondência.

IIDepartamento de Ciência do Solo, Escola Superior de Agricultura Luiz de Queiroz (ESALQ/USP), Piracicaba, SP, Brasil.

IIIDepartamento de Solos, UFSM, Santa Maria, RS, Brasil. 
demanda por conhecimentos mais específicos em relação à sua gênese, mineralogia, química, física e morfologia, a fim de se evitar a degradação das áreas exploradas (PEDRON et al., 2009).

O Estado do Rio Grande do Sul (RS) apresenta regiões fisiográficas caracterizadas por particularidades em relação ao clima e a geologia, as quais afetam a gênese dos solos (KÄMPF \& SCHWERTMANN, 1983). O RS possui, aproximadamente, $20 \%$ do seu território constituído por Neossolos Litólicos e Regolíticos (BRASIL, 1973). Estudos detalhados de gênese e mineralogia para solos bem desenvolvidos, como os Latossolos, são facilmente encontrados (KÄMPF \& KLAMT, 1978; PÖTTER \& KÄMPF, 1981), entretanto, trabalhos que abordam Neossolos são restritos (KÄMPF et al., 1995a). O conhecimento das diferenças químicas e mineralógicas entre os Neossolos, impostas pelo ambiente de formação, é fundamental para o entendimento do comportamento desses solos quando submetidos ao uso agrícola.

Sendo assim, este trabalho teve como objetivo determinar o grau de intemperismo de Neossolos Litólicos e Neossolos Regolíticos através do estudo das alterações dos minerais em perfis de solos dispostos em uma climo-litossequência no Planalto do RS.

\section{MATERIAL E MÉTODOS}

Foram estudados cinco perfis (P1, P2, P3, P4 e P5) dispostos em uma climo-litossequência sobre a extremidade Sul da Formação Serra Geral, na Bacia do Paraná, RS. Os pontos encontram-se em um transeto de $600 \mathrm{~km}$, na direção Oeste-Leste, seguindo aproximadamente o paralelo $29^{\circ} \mathrm{Sul}$. Dados ambientais são encontrados na figura 1. A descrição morfológica dos perfis seguiu a proposta de SANTOS et al. (2005).

A cor foi determinada pela caderneta de Munsell, após seca e moída, evitando-se variações naturais na luminosidade e umidade de campo. A granulometria da fração fina (terra fina seca ao ar) foi determinada pelo método da pipeta (EMBRAPA, 1997). Os dados de química de rotina, utilizados para a classificação dos perfis de Neossolos e, por isso, não mostrados no trabalho, foram realizados conforme recomendações da EMBRAPA(1997).

As amostras de terra fina foram submetidas à extração com ácido sulfúrico $\left(\mathrm{H}_{2} \mathrm{SO}_{4}\right)$ concentrado na proporção 1:1 e os teores de $\mathrm{Fe}, \mathrm{Al}$ e $\mathrm{Si}\left(\mathrm{Fe}_{\mathrm{s}}, \mathrm{Al}_{\mathrm{s}}\right.$ e $\mathrm{Si}$ ) foram determinados no extrato por espectrometria de absorção atômica (EAA) (EMBRAPA, 1997). Essas informações permitiram o cálculo das relações moleculares ki e kr e foram tomadas como uma estimativa da composição química de minerais secundários na fração argila(EMBRAPA, 1997). O Fe e oAl foram também extraídos com solução de citrato tribásico de sódio dihidratado, bicarbonato de sódio e ditionito de sódio (DCB) (MEHRA \& JACKSON, 1960), e com solução de oxalato de amônio (OA) 0,2mol L-1 em meio ácido (pH3,0), no escuro (MCKEAGUE \& DAY, 1966). A concentração de Fe e Al nos extratos de DCB $\left(\mathrm{Fe}_{\mathrm{d}}\right.$ e $\left.\mathrm{Al}_{\mathrm{d}}\right)$ e OA$\left(\mathrm{Fe}_{\mathrm{o}}\right.$ e $\left.\mathrm{Al}_{0}\right)$ foram determinados por EAA.

As amostras para difração de raios $\mathrm{X}$ foram preparadas de acordo com EMBRAPA (1997). As amostras de rocha, saprolito e silte foram analisadas em pó e as de argila em lâminas orientadas. As amostras de argila foram saturadas com $\mathrm{K}^{+}$e analisadas antes ( $\mathrm{K}^{+}$a temperatura ambiente) e após tratamentos térmicos $\left(\mathrm{K}^{+}\right.$a $350^{\circ} \mathrm{C}, \mathrm{K}^{+}$a $\left.550^{\circ} \mathrm{C}\right)$; saturadas com $\mathrm{Mg}^{2+}$ e analisadas a temperatura ambiente, e após solvatação com etileno-glicol; analisadas após desferrificação com DCB e posterior saturação com $\mathrm{K}^{+}$. O equipamento utilizado foi um difratômetro de raios $\mathrm{X}$ operando com ânodo de cobre (Cu Ká 0,154nm) e filtro de niquel, velocidade de varredura de $1,2^{\circ} 2$ èmin $^{-1}$, faixa de varredura de $3^{\circ}$ a $65^{\circ}$ 2è nas amostras de argila e silte, e $3^{\circ}$ a $90^{\circ}$ 2è nas amostras de saprolito e rocha, com tensao de aceleração de $40 \mathrm{kV}$ e corrente de $40 \mathrm{~mA}$.

\section{RESULTADOS E DISCUSSÃO}

A sequência geral de horizontes e camadas é A-Cr-R, indicando que os perfis apresentam camadas saprolíticas entre a rocha e o horizonte A, com exceção do P4, que apresentou contato lítico abaixo do horizonte A (Tabela 1). A fração grosseira (>2mm) aumenta do horizonte $\mathrm{A}$ em direção à rocha em todos os perfis. Exceto no P5, há uma tendência de aumento da proporção de argila com a profundidade. Os perfis P1 e P2 apresentaram coloração avermelhada enquanto os perfis $\mathrm{P} 4$ e $\mathrm{P} 5$ brunada, similarmente aos Latossolos avaliados em climossequência semelhante por KÄMPF \& SCHWERTMANN (1983). Conforme estes autores, a coloração avermelhada ou brunada apresenta relação direta com a presença de óxidos de ferro no perfil, discutidas adiante no texto.

Em relação ao $\mathrm{Fe}_{\mathrm{s}}$ (Tabela 1 ), verificou-se que as amostras de terra fina dos perfis derivados de basalto tendem a apresentar valores mais elevados (P1, P2 e P3), e os valores de $\mathrm{Al}_{\mathrm{s}}$ e $\mathrm{Si}_{\mathrm{s}}$ tendem a ser mais elevados nos perfis derivados de riólito-riodacito (P4 e P5), corroborando estudos anteriores (KÄMPF \& DICK, 1984; KER \& RESENDE, 1990), para os solos pouco desenvolvidos (Cambissolos) da região dos Campos de Cima da Serra, RS. Esses valores também estão em concordância com as concentrações totais destes elementos nas rochas de origem (PEATE et al., 1992).

Foram observados valores de ki mais elevados para P1, P2 e P3. Os valores de ki e kr das amostras de terra fina do P4 e P5 são semelhantes aos 


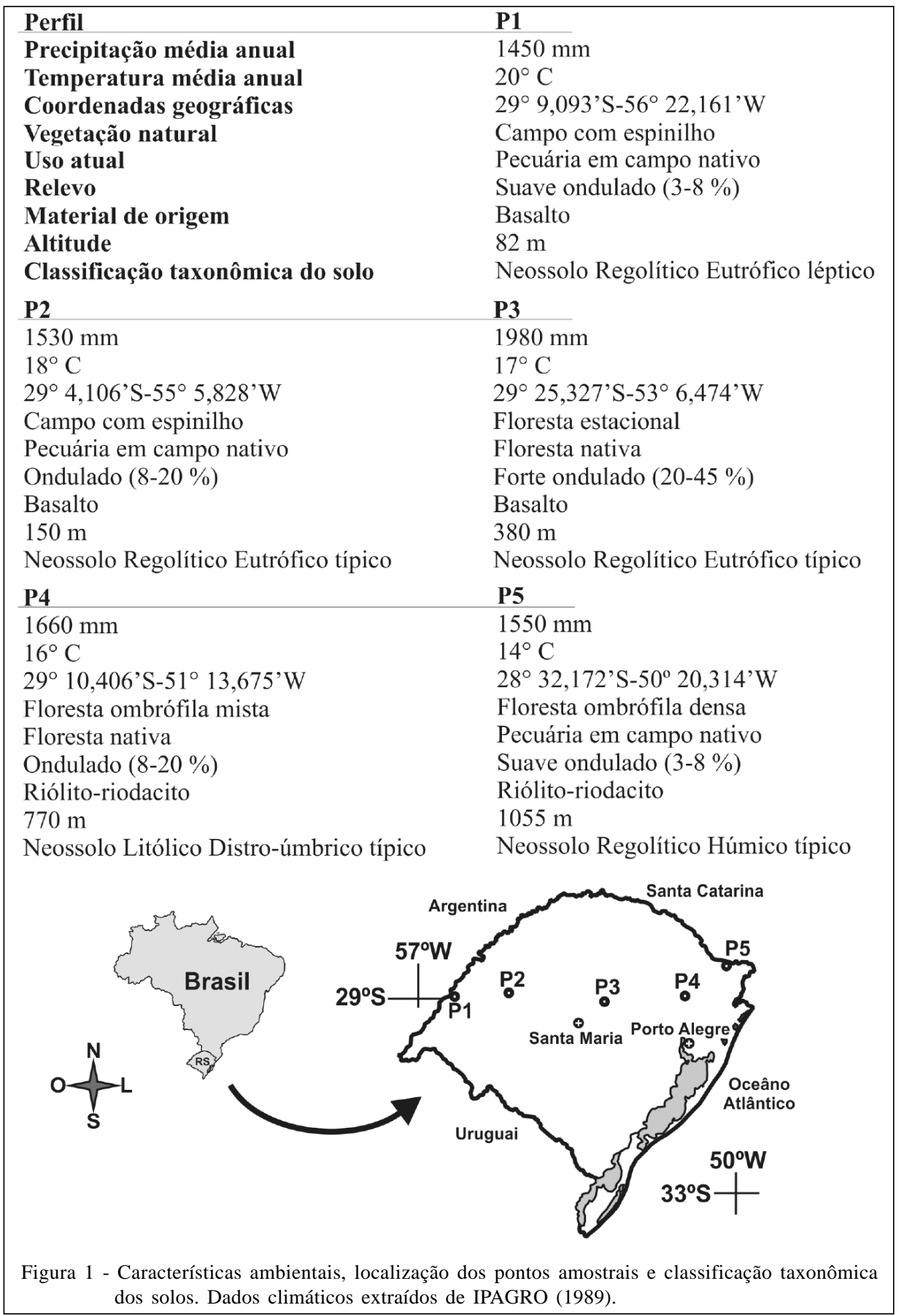

valores de 1,95 e 1,24, respectivamente, encontrados por KER \& RESENDE (1990) em Latossolos da região dos Campos de Cima da Serra, indicando o elevado grau de dessilicação dos Neossolos. Os valores mais elevados de $\mathrm{Fe}_{\mathrm{d}}$ foram observados no P1 e P2. Os teores de Fe variam conforme o material de origem. Rochas mais ácidas como o riólito e o dacito conferem aos solos valores inferiores de $\mathrm{Fe}_{\mathrm{d}}$ que as rochas básicas como o basalto (KÄMPF \& DICK, 1984). Os valores de $\mathrm{Al}_{\mathrm{d}}$, mais elevados para $\mathrm{P} 4 \mathrm{e} \mathrm{P} 5$, também correspondem às características impostas pelas rochas de origens (PEATE et al., 1992).

Os perfis P1, P3 e P4 apresentaram valores inferiores para a relação $\mathrm{Fe}_{\mathrm{d}} / \mathrm{Fe}_{\mathrm{s}}$, variando de 0,3 a 0,4 , enquanto P2 e P5 apresentaram valores entre 0,5 a 0,7. Os valores da relação $\mathrm{Fe}_{\mathrm{d}} / \mathrm{Fe}_{\mathrm{s}}$ encontrados para os cinco 
Tabela 1 - Caracterização morfológica e física dos perfis de Neossolos Regolíticos e Neossolos Litólicos e teores de Fe, Al e Si das amostras de terra fina obtidos pelo ataque sulfúrico, DCB e oxalato ácido de amônio e índices ki e kr.

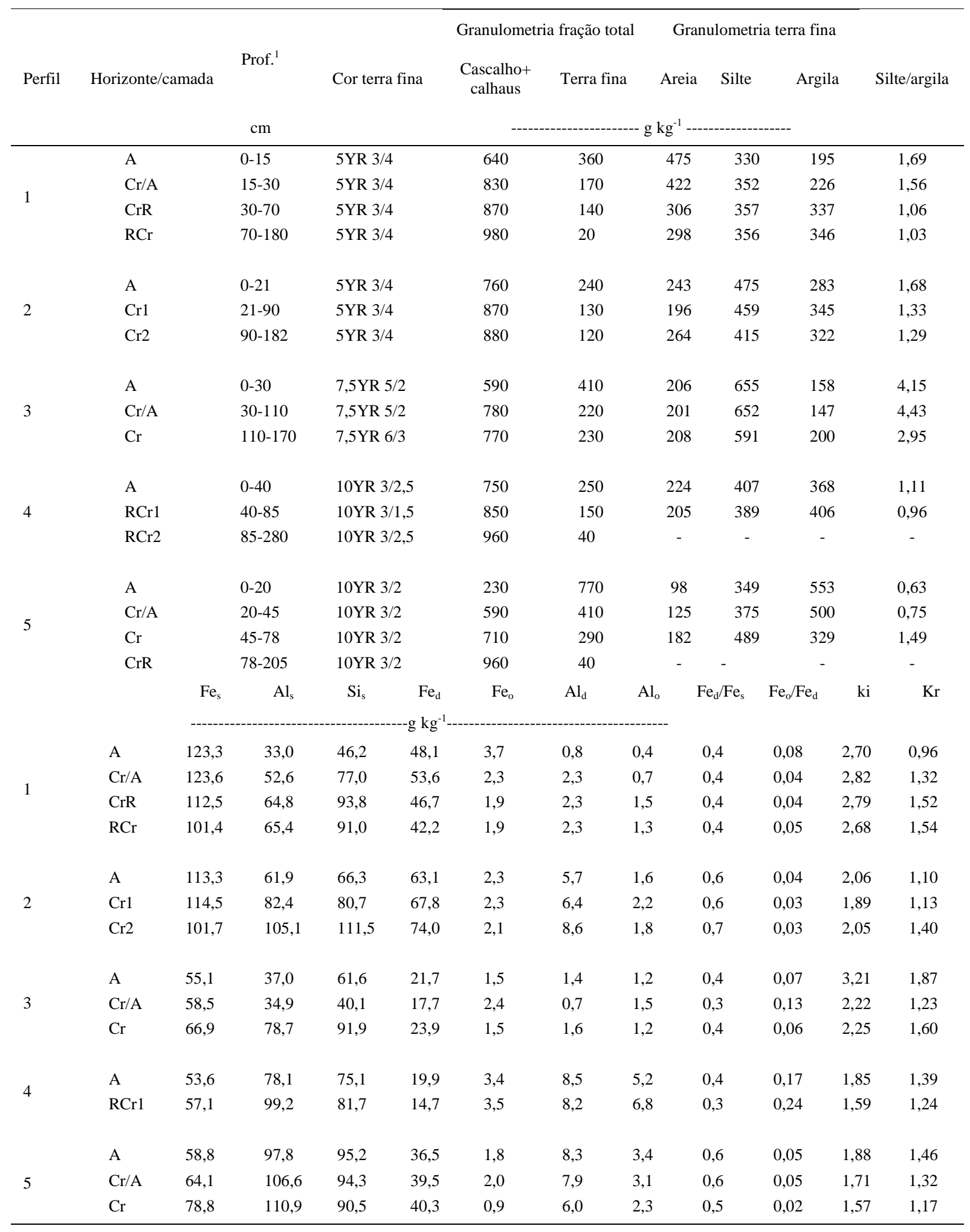

\footnotetext{
${ }^{1}$ Profundidade.
} 
perfis são inferiores aos encontrados para Latossolos do RS (0,85-0,99, KÄMPF \& DICK, 1984; e 0,7-1,0, DALMOLIN et al., 2006). No entanto, esses valores são próximos dos encontrados por KÄMPF \& DICK (1984) para horizonte B de Cambissolos do Nordeste do RS $(0,48-0,77)$, em concordância com o menor grau de evolução dos Neossolos em comparação com os Latossolos e grau similar com os Cambissolos.

Os valores da relação $\mathrm{Fe}_{o} / \mathrm{Fe}_{\mathrm{d}}$ apontam para o predomínio de óxidos de Fe cristalinos em todos os perfis, com variação de $98 \%$ no P5 a 76\% no P4. O P4 apresentou maiores teores de Fe oriundos de óxidos de baixa cristalinidade. As relações supracitadas sugerem predomínio de $\mathrm{Fe}$ nos óxidos cristalinos. Valores mais altos de $\mathrm{Al}_{d}$ no P4 e P5 sugerem maior substituição de Fe por Al nos óxidos e oxihidróxidos de $\mathrm{Fe}$ desses perfis, já os valores superiores de $\mathrm{Al}_{\text {o }}$ nos mesmos perfis, devem estar associados à dissolução da gibbsita.

Nos difratogramas da figura 2, observa-se uma tendência de redução da intensidade dos reflexos dos piroxênios, olivinas, magnetita-maghemita e plagioclásios e um aumento da intensidade dos reflexos do quartzo de $\mathrm{P} 1$ em direção à P5. No entanto, houve similaridade na composição das rochas com maior frequência de piroxênios, plagioclásios, feldspatos potássicos, olivinas, biotita, muscovita, magnetitamaghemita e quartzo.

Nas camadas saprolíticas dos perfis P1, P2 e P3, destacaram-se os minerais: clorita, muscovita, feldspato-K, plagioclásio, piroxênio, anfibólio, quartzo, magnetita-maghemita, biotita, olivina, anatásio, esmectita, caulinita, hematita, goethita, e possivelmente ferrihidrita. O P4 e o P5 diferenciaram-se dos três primeiros perfis pela presença de gibbsita e maior intensidade dos reflexos do quartzo. Além disso, os reflexos dos piroxênios e plagioclásios apresentam menor intensidade no P4 e P5. Os reflexos da caulinita são mais intensos nos três primeiros perfis, indicando que, nos dois últimos perfis, há favorecimento da formação da gibbsita devido às condições de clima e geologia, corroborando as informações de CLEMENTE \& AZEVEDO (2007). A ausência de gibbsita nos materiais derivados de basalto deste trabalho e o fato de KÄMPF \& SCHWERTMANN (1995) terem identificado gibbsita em amostras de saprolitos derivados de basalto e riólitos na região do Planalto Médio e Campos de Cima da Serra, RS, sugerem a ação predominante do clima na promoção de uma taxa de intemperismo mais intensa.

Na fração argila da terra fina, todos os horizontes e camadas do P1 e P3 mostraram difração similar, com destaque para a ilita, caulinita, quartzo, hematita, goethita, magnetita-maghemita, plagioclásio, cristobalita e esmectita-HE (Figura 2).

O pequeno reflexo expandido a $1,80 \mathrm{~nm}$ com o tratamento $\mathrm{Mg}+$ etileno-glicol sugere traços de esmectita na fração argila do P1, P3 e P5. O ombro remanescente entre 1,8 e 1,0nm indica a expansão parcial da esmectita e a possibilidade de esmectita com hidróxiAl entrecamadas (EHE) e interestratificação. No horizonte A do P1, a saturação da amostra com K e aquecimento a $550^{\circ} \mathrm{C}$ promoveu um colapso parcial para $1,0 \mathrm{~nm}$, enquanto as diferenças entre os tratamentos com Mg (não mostrado) e Mg+etileno-glicol foram mínimas, sugerindo o predomínio de esmectitas que ocorrem associadas a uma menor porção de EHE. A hipótese da presença da EHE no P1 é suportada pelo trabalho de KÄMPF et al. (1995a), comprovando a ocorrência de EHE em Neossolos Litólicos na região da Campanha Gaúcha.

A caulinita desordenada foi identificada pelo reflexo a $0,448 \mathrm{~nm}$. A assimetria a partir de $0,715 \mathrm{~nm}$ para ângulos menores, até em torno de 1,0nm, sem alteração com tratamentos como Mg+etileno-glicol e saturação com $\mathrm{K}$ seguido de aquecido a $350^{\circ} \mathrm{C}$ é indicativo de interestratificação caulinita-esmectita (C-E) (SCHULTZ et al., 1971). Foram também identificados reflexos da hematita, principalmente, a 0,269, 0,252, 0,169nm, de goethita a 0,269nm e de magnetita-maghemita a 0,252 e $0,148 \mathrm{~nm}$.

No P5, foi verificada a presença de gibbsita, maior intensidade da goethita e da caulinita e praticamente desaparecimento dos minerais primários, com exceção do quartzo. A ausência de reflexos a 1,0nm indica a alteração das micas existentes no saprolito e na fração silte (dados não mostrados). Os reflexos 0,483 e $0,432 \mathrm{~nm}$ desaparecem na amostra aquecida a $350^{\circ} \mathrm{C}$, confirmando a presença de gibbsita. O mesmo comportamento em relação à interestratificação C-E descrito para o P1 e P3 ocorreu no P5. A intensidade e a largura a meia altura (dado não mostrado) dos reflexos da caulinita indicam menor desordem e maior quantidade desse mineral no P5, quando comparado ao P1 e ao P3. Os valores de $\mathrm{Al}_{\mathrm{s}}$ e $\mathrm{Si}_{\mathrm{s}}$ superiores no P5 contribuem para essa hipótese.

Os reflexos referentes a minerais 2:1 ocorrem predominantemente a $1,40 \mathrm{~nm}$, alterando-se parcialmente na amostra tratada com $\mathrm{K}$ e aquecida a $550^{\circ} \mathrm{C}$. As amostras tratadas com $\mathrm{Mg}+$ etileno-glicol, aparentemente, mantiveram o reflexo a $1,40 \mathrm{~nm}$ no horizonte A e apresentaram pequena expansão na camada Cr até $1,80 \mathrm{~nm}$, sugerindo a presença de esmectita com alto grau de intercalação com polímeros de hidróxi-Al nas entrecamadas. A presença de minerais 2:1 HE foi verificada até em Latossolos Brunos da 


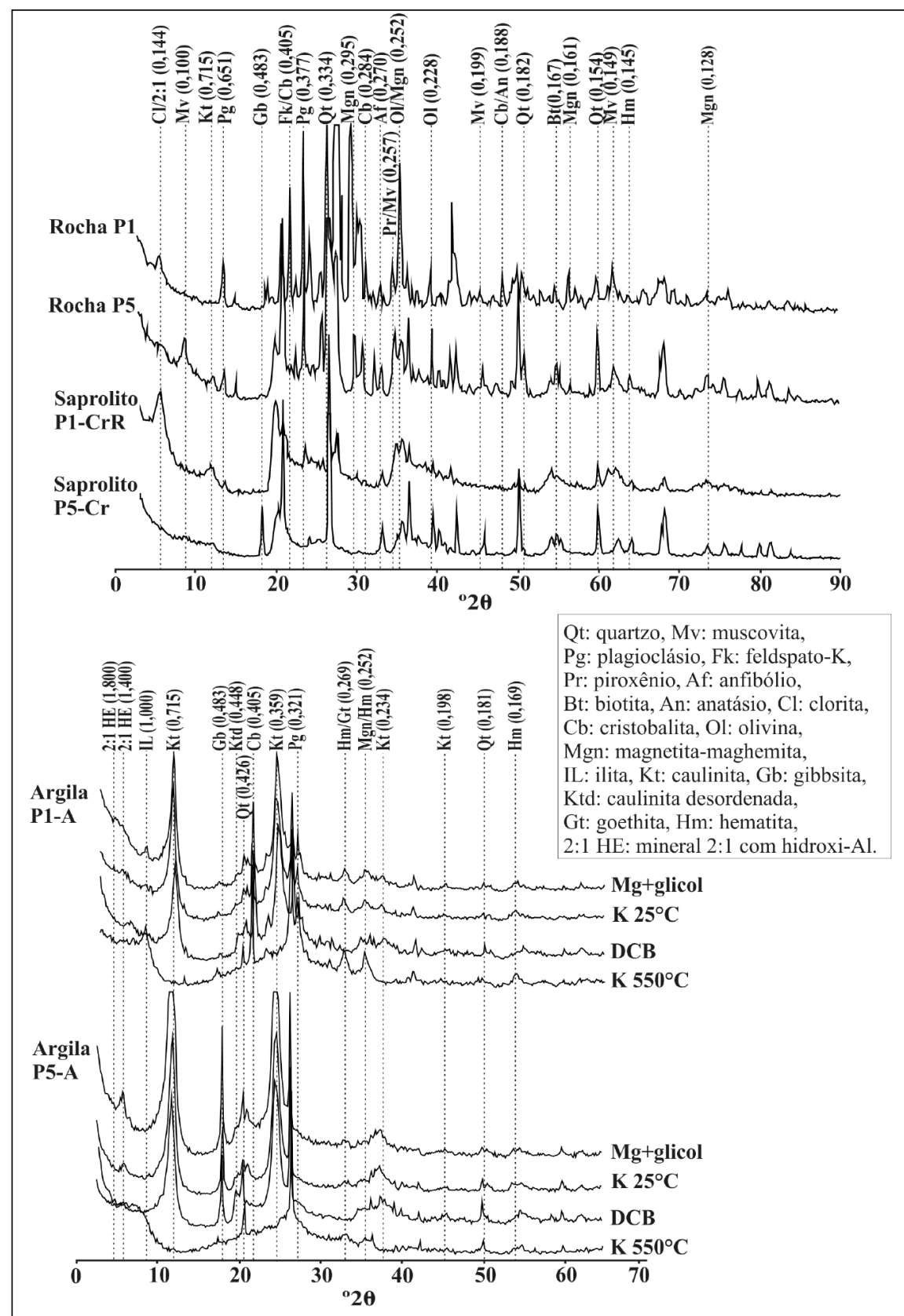

Figura 2 - Difratogramas de raios X de amostras de rocha, saprolito e argilas dos perfis P1 e P5. Distâncias interplanares em nm.

unidade Vacaria, encontrados nos Campos de Cima da Serra, RS (KÄMPF et al., 1995b). Pelos dados verificados no trabalho, a intercalação dos 2:1 com hidroxi-Al ocorre já nos primeiros estágios de intemperismo, mantendo-se estável até estágios mais avançados como nos Latossolos. A elevada estabilidade relativa dos 2:1 HE é explicada por KARATHANASIS (1988). Quanto aos óxidos e oxihidróxidos de ferro no P5, destacou-se a goethita em relação à hematita, o que é também indicado pela cor brunada da fração terra fina do perfil (Tabela 1).

Na fração argila, foi estimado, através da intensidade dos reflexos, um aumento nos teores de caulinita e goethita, associado a uma redução da hematita em direção a P5. O comportamento da caulinita e dos óxidos de Fe nos perfis estudados dá-se em função do clima e do material de origem. De acordo com COSTA et al. (1999), materiais derivados de rochas 
ácidas apresentaram teores mais elevados de caulinita e menores teores de óxidos de $\mathrm{Fe}\left(\mathrm{Fe}_{\mathrm{d}}\right)$, devido às características químicas da rocha. Rochas ácidas favorecem a formação de goethita em detrimento da hematita. O trabalho de KER \& RESENDE (1990) sugere que ambientes úmidos, com baixas temperaturas, baixa evapotranspiração e teores elevados de matéria orgânica em meio ácido e com restrição de drenagem favorecem a formação de goethita em detrimento da hematita e formação de caulinita em detrimento da gibbsita. Essas condições desfavorecem a perda de silício por lixiviação e diminuem a atividade do alumínio pela formação de complexos orgânicos. Ambos os fatores desfavorecem a formação de gibbsita.

Os dados obtidos neste trabalho sugerem dois grupos de solos com graus de intemperismo distintos, baseado nos processos de alteração hidrolíticos apresentados em MELFI \& PEDRO (1977). O primeiro é constituído por P1, P2 e P3 e encontra-se no estágio entre a bissialitização e a monossialitização, caracterizando-se pela predominância de argilominerais 2:1 e 1:1, como a esmectita e a caulinita, respectivamente. Ocorrem óxidos de Fe e os minerais 2:1 são do tipo HE. O segundo, representado por P4 e $\mathrm{P} 5$, encontra-se no estágio entre a monossialitização e a ferralitização, em que predomina a caulinita e óxidos de ferro com aparecimento da gibbsita. A hidrólise parcial sugerida pela presença de 2:1 HE em ambos os grupos indica o grau intermediário de alteração.

Os índices ki e kr sugerem que os perfis $\mathrm{P} 4 \mathrm{e}$ P5 são altamente dessilicatados, no entanto, a relação $\mathrm{Fe}_{\mathrm{d}} / \mathrm{Fe}_{\mathrm{s}}$ aponta um grau de alteração inferior àqueles característicos a solos bem desenvolvidos, como os Latossolos, evidenciando a dificuldade de se aplicar os índices ki e kr para solos com baixo grau de alteração primária, como os Neossolos. Nesses solos, é comum haver uma abundância de fases minerais intermediárias, particularmente de minerais primários em estádio avançado de intemperismo, que podem contribuir com alguns dos elementos químicos determinados pelo ataque sulfúrico.

\section{CONCLUSÃO}

Nas amostras de saprolito, foram identificados teores mais elevados de caulinita no P1, P2 e P3 e de gibbsita no P4 e P5, sugerindo que, no saprolito encontrado em ambiente de alteração intensa, houve predomínio de alteração direta de minerais primários como plagioclásios e feldspatos, encontrados nas rochas, para gibbsita. Na fração argila das amostras de terra fina, houve aumento da caulinita e goethita e redução da hematita em direção ao P5, em decorrência, predominante, das condições climáticas. No P1, P3 e P5, ocorreram minerais 2:1, provavelmente esmectita HE, com aumento da intercalação no P5.

Foram identificados dois grupos de solos com graus de alteração distintos. O primeiro é constituído pelos perfis da porção Oeste da climolitossequência (P1, P2 e P3) e encontra-se no estádio entre a bissialitização e a monossialitização. O segundo é representado pelos perfis da porção Leste (P4 e P5), encontrando-se no estádio entre a monossialitização e a ferralitização. Os índices ki e kr não foram eficientes em representar a condição de alteração secundária dos perfis de Neossolos.

\section{REFERÊNCIAS}

CLEMENTE, C.A.; AZEVEDO, A.C. Mineral weathering in acid saprolites from subtropical, Southern Brazil. Scientia Agricola, v.64, p.601-607, 2007. Disponível em: <http:// www.scielo.br/pdf/sa/v64n6/a07v64n6.pdf>. Acesso em: 30 set. 2010. doi: 10.1590/S0103-90162007000600007.

COSTA, A.C.S. et al. Quantification and characterization of maghemite in soils derived from volcanic rocks in southern Brazil. Clays and Clay Minerals, v.47, p.466-473, 1999.

DALMOLIN, R.S.D. et al. Organic matter characteristics and distribution in Ferralsol profiles of a climosequence in southern Brazil. European Journal of Soil Science, v.57, p.644654, 2006. Disponível em: <http://web.ebscohost.com/ehost/ pdfviewer $/$ pdfviewer? vid=4\&hid=10\&sid=8c407eca-de2e45b2-97c1-4062f4aa6cb7\%40sessionmgr12>. Acesso em: 30 set. 2010. doi: 10.1111/j.1365-2389.2006.00755.x.

EMBRAPA. EMPRESA BRASILEIRA DE PESQUISA AGROPECUÁRIA. Centro Nacional de Pesquisa de Solos. Manual de métodos de análise de solos. 2.ed. Rio de Janeiro: EMBRAPA, 1997. 221p.

EMBRAPA. EMPRESA BRASILEIRA DE PESQUISA AGROPECUÁRIA. Centro Nacional de Pesquisa de Solos. Sistema brasileiro de classificação de solos. 2.ed. Rio de Janeiro: EMBRAPA, 2006. 306p.

IPAGRO. Instituto de Pesquisas Agropecuárias. Seção de ecologia agrícola. Atlas agroclimático do Estado do Rio Grande do Sul. Porto Alegre: IPAGRO. 1989. V.1, 102p.

KÄMPF, N.; KLAMT, E. Mineralogia e gênese de Latossolos (Oxisols) e solos podzólicos da região nordeste do Planalto SulRiograndense. Revista Brasileira de Ciência do Solo, v.2, p.68-78, 1978.

KÄMPF, N.; DICK, D.P. Óxidos de ferro em Cambissolos Brunos do Rio Grande do Sul e Sul de Minas Gerais. Revista Brasileira de Ciência do Solo, v.8, p.183-188, 1984.

KÄMPF, N. et al. Alteração mineralógica em sequência Vertissolo-Litossolo na região da Campanha no Rio Grande do Sul. Revista Brasileira de Ciência do Solo, v.19, p.349357, 1995a. 
KÄMPF, N. et al. Estrutura básica de argilominerais 2:1 com hidróxi-Al entrecamadas em Latossolos Bruno do Rio Grande do Sul. Revista Brasileira de Ciência do Solo, v.19, p.185190, $1995 b$.

KÄMPF, N.; SCHWERTMANN, U. Goethite and hematite in a climossequence in southern Brazil and their application in classification of kaolinitic soils. Geoderma, v.29, p.27-39, 1983.

KÄMPF, N.; SCHWERTMANN, U. Goethitas na interface solorocha em amostras do Rio Grande do Sul e Minas Gerais. Revista Brasileira de Ciência do Solo, v.19, p.359-366, 1995.

KARATHANASIS, A.D. Compositional and solubility relationships between aluminum-hydroxinterlayered soilsmectites and vermiculites. Soil Science Society of America Journal, v.52, p.1500-1508, 1988.

KER, J.C.; RESENDE, M. Caracterização química e mineralógica de solos brunos subtropicais do Brasil. Revista Brasileira de Ciência do Solo, v.14, p.215-225, 1990.

McKEAGUE, J.A.; DAY, J.H. Dithionite and oxalate extractable $\mathrm{Fe}$ and $\mathrm{Al}$ as aids in differentiating various classes of soil. Canadian Journal of Soil Science, v.46, p.13-22, 1966.

MEHRA, O.P.; JACKSON, M.L. Iron oxide removal from soils and clays by a dithionite-citrate system buffered with sodium bicarbonate. Proceedings Clays \& Clay Mineral Conference, v.7, p.317-327, 1960.

MELFI, A.J.; PEDRO, G. Estudo geoquímico dos solos e formações superficiais do Brasil. Parte 1: caracterização e repartição dos principais tipos de evolução pedogeoquímica. Revista Brasileira de Geociências, v.7, p.271-286, 1977.

PEATE, D.W. et al. Chemical stratigraphy of the Parana lavas (South America): classification of magma types and their spatial distribution. Bulletin of Vulcanology, v.55, p.119-139, 1992.

PEDRON, F. de A. et al. Morfologia e classificação taxonômica de Neossolos e saprolitos derivados de rochas vulcânicas da formação Serra Geral no Rio Grande do Sul. Revista Brasileira de Ciência do Solo, v.33, p.119-128, 2009. Disponível em: <http://www.scielo.br/pdf/rbcs/v33n1/13.pdf >. Acesso em: 30 set. 2010. doi: 10.1590/S0100-06832009000100013.

PÖTTER, R.O.; KÄMPF, N. Argilo-minerais e óxidos de ferro em Cambissolos e Latossolos sob regime climático térmico údico no Rio Grande do Sul. Revista Brasileira de Ciência do Solo, v.5, p.153-159, 1981.

SANTOS, R.D. et al. Manual de descrição e coleta de solo no campo. 5.ed. Viçosa: SBCS, 2005. 100p.

SCHULTZ, L.G. et al. Mixed-layer kaolinite-montmorillonite from the Yucatán peninsula, México. Clays and Clay Minerals, v.9, p.137-150, 1971. 